\title{
Quantal Size Is Independent of the Release Probability at Hippocampal Excitatory Synapses
}

\author{
Ágota A. Biró, Noémi B. Holderith, and Zoltan Nusser \\ Laboratory of Cellular Neurophysiology, Institute of Experimental Medicine, Hungarian Academy of Sciences, 1083 Budapest, Hungary
}

Short-term synaptic plasticity changes the reliability of transmission during repetitive activation and allows different neuronal ensembles to encode distinct features of action potential trains. Identifying the mechanisms and the locus of expression of such plasticity is essential for understanding neuronal information processing. To determine the quantal parameters and the locus of alterations during short-term plasticity of cortical glutamatergic synapses, EPSCs were evoked in hippocampal oriens-alveus interneurons by CA1 pyramidal cells. The robust short-term facilitation of this connection allowed us to examine the transmission under functionally relevant but widely different release probability $\left(P_{\mathrm{r}}\right)$ conditions. Paired whole-cell recordings permitted the functional and post hoc morphological characterization of the synapses. To determine the quantal size $(q)$, the $P_{\mathrm{r}}$, and the number of functional release sites $\left(N_{\mathrm{F}}\right)$, two independent quantal analysis methods were used. Light and electron microscopy were performed to identify the number of synaptic junctions $\left(N_{\mathrm{EM}}\right)$ between the recorded cells. The mean number of functional release sites $\left(N_{\mathrm{F}(\mathrm{f})}=2.9 \pm 0.4 ; n=8\right)$ as inferred from a simple binomial model with no quantal variance agreed well with the mean of $N_{\mathrm{EM}}(2.8 \pm 0.8 ; n=6)$, but $N_{\mathrm{F}(\mathrm{f})}$ never matched $N_{\mathrm{EM}}$ when they were compared in individual pairs; however, including quantal variance in the model improved the functional prediction of the structural data. Furthermore, an increased $P_{\mathrm{r}}(4.8 \pm 0.8$-fold $)$ fully accounted for the marked short-term facilitation of EPSCs (5.0 \pm 0.7 -fold), and $q$ was independent of $P_{\mathrm{r}}$. Our results are consistent with the "one-release site, one-vesicle" hypothesis.

Key words: patch clamp; paired recordings; electron microscopy; quantal analysis; hippocampus; interneurons

\section{Introduction}

The work of Katz and his colleagues (del Castillo and Katz, 1954b) has demonstrated that synapses are not static transmitting devices but dynamic links displaying plastic behaviors. It has been suggested that information processing is strongly influenced by the reliability and short-term plasticity of synapses (Abbott et al., 1997; Tsodyks and Markram, 1997; Zador, 1998; Pouille and Scanziani, 2004). For example, neuronal networks containing recurrent inhibitory circuits can discriminate between distinct temporal features of action potential (AP) trains. A differential short-term plasticity of excitatory synapses to GABAergic interneuron (IN) subtypes plays a key role in this process (Pouille and Scanziani, 2004). Thus, understanding what determines the type of short-term plasticity, the locus of alterations, and how the plasticity pattern can be changed is essential for deciphering the cellular and molecular basis of cortical information processing.

Revealing the locus of alterations during synaptic plasticity

Received Sept. 7, 2004; revised 0ct. 27, 2004; accepted Nov. 15, 2004.

Z.N. is the recipient of a Wellcome Trust International Senior Research Fellowship, an International Scholarship from Howard Hughes Medical Institute, a Postdoctoral Fellowship from the Boehringer Ingelheim Fond, and a research grant from the Human Frontier Science Program. The financial support from these foundations is gratefully acknowledged. We thank Drs. Mark Eyre, Mark Farrant, Istvan Mody, and Angus Silver for their comments on this manuscript.

Correspondence should be addressed to Zoltan Nusser, Laboratory of Cellular Neurophysiology, Institute of Experimental Medicine, Hungarian Academy of Sciences, Szigony Street 43, 1083 Budapest, Hungary. E-mail: nusser@koki.hu.

D0I:10.1523/JNEUROSCI.3688-04.2005

Copyright $\odot 2005$ Society for Neuroscience $\quad$ 0270-6474/05/250223-10\$15.00/0 has been facilitated by the development of quantitative models (del Castillo and Katz, 1954a; Tsodyks and Markram, 1997; Varela et al., 1997; Dittman et al., 2000). The most widely accepted model (quantal) (del Castillo and Katz, 1954a) successfully describes transmission at the neuromuscular junction. Katz's hypothesis that neurotransmitters are released in discrete quanta in a probabilistic manner has been widely accepted to be true also at central synapses. Classic quantal analysis, however, has been successfully applied only in a handful of studies to determine the number of release sites $(N)$, probability of transmitter release $\left(P_{\mathrm{r}}\right)$, and quantal size $(q)$, as well as to identify the locus of alterations during synaptic plasticity in the CNS (Redman, 1990; Jack et al., 1994; Korn et al., 1994). To overcome the shortcomings of classic quantal analysis, new analysis methods were developed (Clements and Silver, 2000). Possibly an even more successful avenue has been the combination of electrophysiological recordings with either anatomical or imaging techniques. For example, paired recordings with subsequent light microscopic (LM) and electron microscopic (EM) analysis of the number of synaptic contacts have been successful approaches to obtain independent estimates of $N$ (Korn et al., 1982; Gulyas et al., 1993; Buhl et al., 1997; Silver et al., 2003). Alternatively, two-photon imaging of calcium transients in single spines (Oertner et al., 2002; Nimchinsky et al., 2004) and imaging of the destaining rate of FM1-43 fluorescence (Murthy et al., 1997) have been used to monitor $P_{\mathrm{r}}$ independently of electrophysiological recordings.

It is widely accepted that short-term plasticity is accompanied by changes in $P_{\mathrm{r}}$ (for review, see Thomson, 2000; Zucker and 
Regehr, 2002); however, whether alterations in $P_{\mathrm{r}}$ (purely presynaptic) fully account for such plasticity (Gulyas et al., 1993; Paulsen and Heggelund, 1994; Stevens and Wang, 1995; Hanse and Gustafsson, 2001; Silver et al., 2003; Lawrence et al., 2004) or whether postsynaptic alterations also occur (Otis et al., 1996; Rozov and Burnashev, 1999; Oleskevich et al., 2000; Oertner et al., 2002; Harrison and Jahr, 2003) is still a question of active debate. To determine the quantal parameters and the locus of alterations during short-term facilitation at cortical glutamatergic synapses, we took advantage of the robust facilitation of synapses made by hippocampal CA1 pyramidal cells (PCs) onto specific subtypes of interneurons (Ali and Thomson, 1998; Scanziani et al., 1998; Losonczy et al., 2002). Because this facilitation is accompanied by a large change in $P_{\mathrm{r}}$ (Ali and Thomson, 1998), we could study this connection under physiologically relevant but highly diverse $P_{\mathrm{r}}$ conditions. Our results demonstrate a sole presynaptic change during short-term facilitation and are consistent with the "one-release site, one-vesicle" hypothesis.

\section{Materials and Methods}

Acute slice preparation for electrophysiological recordings. One hundred thirty male Wistar rats (14-21 d old) were anesthetized first with halothane and then with ketamine (50 $\mathrm{mg}$ per animal) in accordance with the guidelines of the Institute of Experimental Medicine Protection of Research Subjects. After decapitation, the brain was removed and placed into ice-cold artificial CSF (ACSF) 1 containing (in mM): 230 sucrose, 2.5 $\mathrm{KCl}, 25$ glucose, $1.25 \mathrm{NaH}_{2} \mathrm{PO}_{4}, 24 \mathrm{NaHCO}_{3}, 4 \mathrm{MgCl}_{2}$, and $0.5 \mathrm{CaCl}_{2}$. Horizontal slices were cut at $300 \mu \mathrm{m}$ thickness with a Vibratome (Leica VT1000S; Leica Microsystems, Vienna, Austria) and stored in ACSF 2 containing (in mM): $85 \mathrm{NaCl}, 75$ sucrose, $2.5 \mathrm{KCl}, 25$ glucose, 1.25 $\mathrm{NaH}_{2} \mathrm{PO}_{4}, 24 \mathrm{NaHCO}_{3}, 4 \mathrm{MgCl}_{2}$, and $0.5 \mathrm{CaCl}_{2}$. After $0.5 \mathrm{hr}$, this medium was gradually replaced by ACSF 3 containing (in $\mathrm{mM}$ ): $126 \mathrm{NaCl}$, $2.5 \mathrm{KCl}, 25$ glucose, $1.25 \mathrm{NaH}_{2} \mathrm{PO}_{4}, 24 \mathrm{NaHCO}_{3}, 2 \mathrm{MgCl}_{2}$, and $2 \mathrm{CaCl}_{2}$. All extracellular solutions were bubbled continuously with $95 \% \mathrm{O}_{2}$ and $5 \% \mathrm{CO}_{2}, \mathrm{pH} 7.4$. After $1-7 \mathrm{hr}$ of incubation at $30^{\circ} \mathrm{C}$, the slices were transferred to a recording chamber where they were perfused with ACSF 3 containing the $\mathrm{GABA}_{\mathrm{A}}$ receptor antagonist 2-(3-carboxypropyl)-3-amino-6(4-methoxyphenyl)-pyridazinium bromide (SR95531) (20 $\mu \mathrm{M})$. Recordings were performed at $32-36^{\circ} \mathrm{C}$ (for the cells included in the tables: $33.7 \pm 0.3^{\circ} \mathrm{C} ; n=11$ ). The somata of oriens-alveus INs and PCs were identified with an infrared differential interference contrast (DIC) technique using an Olympus BX51WI microscope with a $40 \times$ water immersion objective. Interneurons were selected based on their DIC morphology and firing patterns after a 1.5 -sec-long depolarizing current pulse (200 pA). Presynaptic PCs were recorded in the whole-cell currentclamp configuration with a potassium gluconate-based intracellular solution containing (in $\mathrm{mm}$ ): 120 potassium gluconate, $10 \mathrm{~L}$-glutamic acid, $5 \mathrm{KCl}, 2 \mathrm{MgCl}_{2}, 0.05$ EGTA, 10 HEPES, $2 \mathrm{Mg}$-ATP, $0.4 \mathrm{Mg}$-GTP, 10 creatinine phosphate, and 5.3 biocytin, $\mathrm{pH}$ 7.25; osmolality, 270-290 $\mathrm{mmol} / \mathrm{kg}$. In our initial series of experiments, the intracellular solution for PCs did not contain any L-glutamic acid. Ten to forty APs were evoked at $50 \mathrm{~Hz}$ by injecting trains of short $(3 \mathrm{msec})$ depolarizing currents ( $1 \mathrm{nA}$ ) into the PCs. Trains of stimuli were repeated every 15-30 sec, depending on the number of APs within the train. Whole-cell voltageclamp recordings were performed from the postsynaptic INs at a holding potential of $-70 \mathrm{mV}$. The internal solution for INs contained (in $\mathrm{mm}$ ): 130 potassium gluconate, $5 \mathrm{KCl}, 2 \mathrm{MgCl}_{2}, 0.05$ EGTA, 10 HEPES, 2 Mg-ATP, $0.4 \mathrm{Mg}$-GTP, 10 creatinine phosphate, and 5.3 biocytin, $\mathrm{pH}$ 7.25 ; osmolality, $270-290 \mathrm{mmol} / \mathrm{kg}$. Paired whole-cell recordings were performed with a dual-channel amplifier (MultiClamp 700A; Axon Instruments, Foster City, CA). Data were filtered at 3 or $4 \mathrm{kHz}$ (Bessel filter), digitized on-line at $20 \mathrm{kHz}$, and analyzed with EVAN1.3 (Nusser et al., 2001). Patch pipettes (presynaptic 6-8 $\mathrm{M} \Omega$; postsynaptic 2-4 M $\Omega$ ) were pulled (Zeitz Universal Puller; Zeitz-Instrumente Vertriebs, Munich, Germany) from thick-walled borosilicate glass capillaries $(1.5 \mathrm{~mm}$ outer diameter, $0.86 \mathrm{~mm}$ inner diameter; Sutter Instruments, Novato, CA). Series resistance $\left(R_{\mathrm{s}}\right)$ and whole-cell capacitance were checked every
$2 \mathrm{~min}$ in the postsynaptic cell. The mean $R_{\mathrm{s}}$ was $18.4 \pm 1.2 \mathrm{M} \Omega$, and after $60-85 \%$ compensation it was $4.8 \pm 0.3 \mathrm{M} \Omega(n=11)$. All data are expressed as mean \pm SEM. All chemicals and drugs were purchased from Sigma (St. Louis, MO).

Data analysis. The following objective criteria were used to ensure the stationarity of our data during the recordings. The compensated $R_{\mathrm{s}}$ was measured every $2 \mathrm{~min}$; if the slope of a regression line fit to the scatter plot of $R_{\mathrm{s}}$ versus time significantly differed from zero ( $p<0.01 ; t$ test), the recording was discarded. All recordings were rejected when the $R_{\mathrm{s}}$ became $>25 \mathrm{M} \Omega$. The stability of peak amplitudes in time was determined by fitting a regression line to scatter plots of EPSC amplitudes (mean of last four EPSCs of the train) versus time. If the slope of the regression line significantly differed from zero $(p<0.01)$, the recording was discarded. A minimum of 60 trains of EPSCs were required to include a pair in our study (>20 min recording). Reliable determination of quantal parameters requires the measurement of EPSCs under different $P_{\mathrm{r}}$ conditions. We considered different segments of the AP train as distinct $P_{\mathrm{r}}$ conditions. We used either the first AP or the first two APs (in one instance, first fourth) as low $P_{\mathrm{r}}$ conditions and compared the EPSCs with those evoked at the end of the train (usually the 17-20th APs). We measured the failure rates $\left(P_{\mathrm{f}}\right)$ and the amplitudes of the averaged EPSCs excluding failures (potency: $A$ ). In all of the recordings included in this study, the amplitude histogram as measured at the time point of the peak of averaged EPSC clearly showed a multimodal distribution, demonstrating the segregation of failures from successes. According to the binomial statistics, an increase in the $P_{\mathrm{r}}$ results in an increase in the averaged EPSC; however, minute changes in $P_{\mathrm{r}}$ will cause very small enhancements in averaged EPSC amplitudes, which cannot be confidently measured experimentally. Thus, to ensure that a given change in $P_{\mathrm{f}}$ or $P_{\mathrm{r}}$ would result in a confidently measurable change in the potency amplitude (an arbitrary minimum value of 20\%), we discarded all pairs in which the $P_{\mathrm{f}(\text { begin) }} / P_{\mathrm{f}(\text { end })}$ ratio was $<2.5$. Furthermore, if the $P_{\mathrm{r}}$ as calculated with the failure method at the end of the train was $<0.40$, we also discarded the cells.

Quantal analysis with a failure method. From the measured $P_{\mathrm{f}}$ and $A$ at both low and high $P_{\mathrm{r}}$ conditions, a simple binomial model was used to calculate the number of functional release sites $\left(N_{\mathrm{F}(\mathrm{f})}\right), P_{\mathrm{r}}$, and $q$. At the beginning of the train, $q_{(\mathrm{b})}$ was calculated from the measured $P_{\mathrm{f}(\mathrm{b})}$ and $A_{\text {(b) }}$ for integer Ns (practically $1 \leq N \leq 15$ were sufficient for our connections) using Equation 1:

$$
q_{(\mathrm{b})}=\frac{A_{(\mathrm{b})} \cdot\left(1-P_{\mathrm{f}(\mathrm{b})}\right)}{N \cdot\left(1-P_{\mathrm{f}(\mathrm{b})}^{1 / \mathrm{b}}\right)} .
$$

Assuming no change in $q$ during the train of APs ( $q$ independent of $P_{\mathrm{r}}$ ), we calculated the potency amplitude at the end of the train $\left(A_{(\mathrm{e})}\right)$ from $q_{\text {(b) }}$ and $P_{\mathrm{f}(\mathrm{e})}$ for all Ns using Equation 2:

$$
A_{(\mathrm{e})}=\frac{q_{(\mathrm{b})} \cdot N \cdot\left(1-P_{\mathrm{f}(\mathrm{e})}^{1 / N}\right)}{1-P_{\mathrm{f}(\mathrm{e})}} .
$$

The $N_{\mathrm{F}(\mathrm{f})}$ is given by the smallest binomial $N$ at which the calculated $A_{(\mathrm{e})}$ was within $5 \%$ of the measured potency amplitude at high $P_{\mathrm{r}}$ condition (see Figs. $2 C, 3 B, 4 C$ ). For $N_{\mathrm{F}(\mathrm{f})}$, we also calculated $P_{\mathrm{r}}$ at both release probability conditions using Equation 3 (see Table 1):

$$
P_{\mathrm{r}}=1-P_{\mathrm{f}}^{1 / N_{\mathrm{F}}} .
$$

The quantal size for that $N_{\mathrm{F}(\mathrm{f})}$ is also given in Table 1 .

Multiple probability fluctuation analysis. We performed multiple probability fluctuation analysis (MPFA) according to the published method of Silver (2003). A multinomial quantal model based on the following assumptions was used: independent release sites, uniform $P_{\mathrm{r}}$ across release sites, and $q$ is independent of $P_{\mathrm{r}}$. Type I (intrasite) and II (intersite) quantal variances were incorporated into the model.

The intrasite (type I) coefficient of variation $(\mathrm{CV}=\mathrm{SD} /$ mean $)$ was derived from anatomically defined single-site connections (AB378: $\mathrm{CV}=0.41 ; \mathrm{AB} 390: \mathrm{CV}=0.40$; measured as the $\mathrm{CV}$ of successful EPSCs) that were assumed to be the same for the individual release sites of the multisite connections. Type II quantal variance was calculated from those multisite pairs in which the initial $P_{\mathrm{f}}$ was sufficiently high $(0.87$, 
0.82 , and 0.81 for three cells) that simultaneous release from more than one release site did not occur among successful events. Under these conditions the total variance is the sum of intersite and intrasite variances:

$$
C V_{\mathrm{II}}^{2}=C V_{\mathrm{T}}^{2}-C V_{\mathrm{I}}^{2}
$$

where $C V_{\mathrm{T}}, C V_{\mathrm{I}}$, and $C V_{\mathrm{II}}$ are the total, type I, and type II quantal coefficients of variations, respectively. The CV of the peak of the successful EPSCs $\left(C V_{\mathrm{T}}\right)$ was measured in these three pairs. Type II CV of $0.37 \pm$ 0.08 was calculated from Equation 4 . The peak amplitude of individual EPSCs as well as the failures were measured at each AP of the train, and their means and variances were calculated. The baseline variance $\left(\sigma_{(\mathrm{b})}{ }^{2}\right)$ was measured 1-2 msec before the onset of the averaged postsynaptic response. The variance $\left(\sigma^{2}\right)$ can be expressed as a function of mean current $(I)$ using the following relationship:

$$
\sigma^{2}=\sigma_{(\mathrm{b})}^{2}+\left(q I-I^{2} / N_{\mathrm{F}(\mathrm{MPFA})}\right)\left(1+C V_{\mathrm{II}}^{2}\right)+q I C V_{\mathrm{I}}^{2} .
$$

After $\sigma_{(\mathrm{b})}{ }^{2}$ subtraction, the variance versus mean current plot was fitted with a parabola using Origin 7.0 (OriginLab Corporation, Northhampton, $\mathrm{MA}$ ) in each pair, and $N_{\mathrm{F}(\mathrm{MPFA})}$ was rounded to an integer number (see Table 2). For the single-site connection, type II quantal variance was obviously not included in the model. The $P_{\mathrm{r}}$ was calculated at the beginning and end of the train by dividing the measured currents by the maximum current (obtained from the parabola). Because in these synapses the mean $P_{\mathrm{r}}$ at the end of the train was not larger than $\sim 0.5$, the mean and variance values were obtained only at the first half of the parabola. Fitting a parabola to data points at ranges of $P_{\mathrm{r}}$ from 0 to 0.5 is prone to sampling errors (Silver, 2003). To estimate the possible errors in our estimated $N_{\mathrm{F}(\mathrm{MPFA})}$ and $q$, we performed a series of Monte Carlo simulations. One hundred eighty (the mean number of traces in our experiments for low and high $P_{\mathrm{r}}$ conditions) random numbers were generated with binomial $p$ of $0.15,0.25,0.35$, and 0.5 for $N$ s ranging from 1 to 5 . When the binomial numbers were not zero, $q$ was randomly selected from a normal distribution with a mean of 40 (mean $q$ in our experiments) and an SD of 16 (the mean SD at the single sites). Forty simulations were performed for each binominal $p$ and $N$ (800 in total). The means and variances were calculated for each simulation, and the mean versus variance plots were fitted in Origin to obtain the $N$ and $q$ values. In $49 \%$ of the cases, $N_{\mathrm{F}(\mathrm{MPFA})}$ was identical to the binomial $N$, and in $33 \%$ of the simulations MPFA underestimated or overestimated the $N$ by 1 . The error was dependent on the $N$. For binomial $N=1, N_{\mathrm{F} \text { (MPFA) }}$ was correct in $95 \%$ of the simulations. For $N=3$, which is the mean number of $N_{\mathrm{EM}}$ in our study, in $40 \%$ of the cases MPFA correctly estimated the $N$, and in $50 \%$ of the cases the error was \pm 1 . Our simulations indeed confirm the data of Silver (2003) and indicate that the chance is $\sim 50 \%$ that MPFA correctly estimates the $N_{\mathrm{F}}$ and an additional $31 \%$ that the error in the estimated $N$ is \pm 1 . We also tested the reliability of MPFA in estimating $q$ and found that it overestimates $q$ by $\sim 17 \%$ ( $47.1 \pm 0.2$ vs 40 ) in our modeling. This seems to be independent of the binominal $N$. Indeed, the $q$ as calculated with MPFA without any quantal variance (49.7 pA) was larger than that obtained with the failure method (39.7 $\mathrm{pA}$ ), whereas including type I and II quantal variances into the MPFA reduced the estimated $q$ to $37.4 \mathrm{pA}$.

EM identification of the synaptic junctions. After recordings, slices were placed in a fixative containing $4 \%$ paraformaldehyde, $1 \%$ glutaraldehyde, and $\sim 0.2 \%$ picric acid in $0.1 \mathrm{M}$ phosphate buffer $(\mathrm{PB}), \mathrm{pH} 7.4$, at $4^{\circ} \mathrm{C}$. Before processing, the fixative was thoroughly washed out with $0.1 \mathrm{M}$ PB. Slices were then cryoprotected in 10 and $20 \%$ sucrose (in $0.1 \mathrm{M} \mathrm{PB}$ ) for 30 min followed by freezing in liquid nitrogen and thawing in PB. After several washes in PB, slices were embedded in gelatin and resectioned at $60 \mu \mathrm{m}$ thickness. Biocytin was visualized using avidin-biotin HRP complex (Vector Laboratories, Burlingame, CA) followed by peroxidase reaction with $3^{\prime} 3$-diaminobenzidine tetrahydrochloride $(0.05 \%$ solution in Tris buffer, $\mathrm{pH} 7.4)$ as chromogen and $0.01 \% \mathrm{H}_{2} \mathrm{O}_{2}$ as oxidant for $12 \mathrm{~min}$. Sections were then postfixed in $1 \% \mathrm{OsO}_{4}$ for $20 \mathrm{~min}$, stained in $1 \%$ uranyl acetate for $30 \mathrm{~min}$, dehydrated in a graded series of ethanol, and embedded in epoxy resin (Durcupan, Sigma).

First, the recorded cells were analyzed at LM level. A pair was discarded if the presynaptic pyramidal cell or the dendrites of the postsynaptic IN were not fully and strongly labeled or if they displayed any obvious truncation. The truncation of axons of the postsynaptic INs did not result in the rejection of the pair. Given that the completeness of biocytin filling (with the exception of the IN axon) and full recovery (no loss of tissue with parts of filled cells during processing) were firmly established (in 8 of 28 pairs), the axonal and dendritic arbors were thoroughly analyzed at high LM magnifications $(100 \times$ objective; numerical aperture $=1.35)$. Potential synaptic contacts were identified as close $(<1 \mu \mathrm{m})$ appositions of presynaptic boutons and postsynaptic dendrites. Subsequently, neurons were fully reconstructed with the aid of a drawing tube attached to an Olympus DP51 microscope or with a NeuroLucida system (MicroBrightField Europe, Magdeburg, Germany) attached to a Zeiss Axioscope 2 microscope. After detailed LM imaging (with an Olympus DP70 digital camera) of the possible contact sites at several (20-30) slightly different $(0.5 \mu \mathrm{m})$ focus planes, the areas with possible contact sites were re-embedded and trimmed, and serial ultrathin (60 nm thickness) sections were cut. The filled presynaptic and postsynaptic profiles were followed from section to section and recorded using a digital camera (MegaViewII or Cantega, Soft Imaging System, Munster, Germany). If a presynaptic terminal made a direct contact with the postsynaptic cell dendrite, the following criteria were used to classify the contact as a synaptic junction: (1) rigid apposition of presynaptic and postsynaptic membranes, (2) widening of the extracellular space in the synaptic cleft, and (3) clustering of small synaptic vesicles at the release site. The presence of postsynaptic density as a relatively electron-pale area at the cytoplasmic face of the postsynaptic membrane was sometimes also visible.

\section{Results}

To restrict the activation to only one presynaptic fiber and to visualize the stimulated synapses, paired whole-cell recordings between CA1 PCs and oriens-alveus INs [mainly oriens lacunosum-moleculare (O-LM) and some oriens bistratified (O$\mathrm{Bi}$ ) ] were performed in acute hippocampal slices of juvenile rats (postnatal days $14-21)$ at $34^{\circ} \mathrm{C}$. Short $(2-3 \mathrm{msec})$ depolarizing current pulses were injected into the PCs at $50 \mathrm{~Hz}$, and the corresponding EPSCs were recorded from the INs in the whole-cell voltage-clamp configuration in the presence of the $\mathrm{GABA}_{\mathrm{A}}$ receptor antagonist SR95531 $(20 \mu \mathrm{M})$. More than 650 double recordings were performed, and monosynaptic connections were found in 53 cases. In $94 \%$ of these connections ( 50 of 53), EPSCs showed short-term facilitation, demonstrating that O-LM or O-Bi INs were successfully preselected as postsynaptic cells based on their voltage responses to long depolarizing and hyperpolarizing current injections (see Fig. 4F) (Losonczy et al., 2002).

In our initial experiments, EPSCs disappeared almost completely within the first 5-10 min after the whole-cell configuration was established in six of eight connected pairs (Fig. $1 A$ ). Such a robust rundown of postsynaptic responses when cells were recorded in the whole-cell configuration was reported by Kondo and Marty (1998) and Ishikawa et al. (2002). Meanwhile, the amplitudes of spontaneously occurring EPSCs recorded from the postsynaptic INs were stable within this period (data not shown). Therefore, we concluded that intracellular dialysis of the presynaptic cell is likely to be responsible for the rundown. Ishikawa et al. (2002) reported that the rundown of postsynaptic EPSCs at the calyx of Held could be prevented by the inclusion of $10 \mathrm{~mm}$ L-glutamic acid into the internal solution of the presynaptic cell. We repeated this protocol and were able to obtain stable postsynaptic responses for at least $20 \mathrm{~min}$ in 17 pairs (Fig. $1 \mathrm{~B}$ ). The remaining 25 pairs were discarded from our analysis because either there was an increase in the access resistance or the recording lasted for $<20 \mathrm{~min}$ (for criteria, see Materials and Methods).

Of the 17 pairs in which sufficiently long and stable recordings were obtained, 8 more pairs were discarded because the change in $P_{\mathrm{f}}$ during the AP train was not adequately large $(>150 \%)$, and 

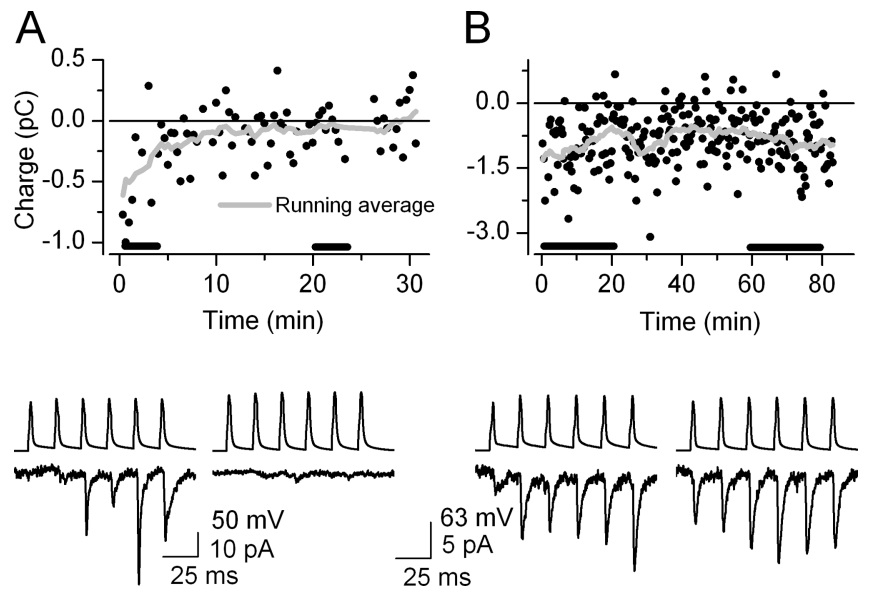

Figure 1. Rundown of postsynaptic responses during paired whole-cell recordings is prevented by the presynaptic application of $10 \mathrm{~mm}$ L-glutamic acid. $A$, Top panel, Charge of EPSCs is plotted against time during 30 min of paired recordings without L-glutamic acid in the presynaptic internal solution. Bottom panel, Six presynaptic action potentials and the corresponding averaged EPSCs at the beginning and end of the recordings. B, Top panel, L-glutamic acid (10 $\mathrm{mm}$ ) in the presynaptic intracellular solution prevented the rundown of unitary EPSCs. Bottom panel, Averaged postsynaptic responses are virtually the same at the beginning and end of an 80 min recording.

therefore the connection was not considered dynamic enough (see Materials and Methods). In the remaining nine pairs, which have passed all of our objective criteria, we measured the $P_{\mathrm{f}}$, the amplitude of postsynaptic responses excluding failures (potency), and the averaged EPSC amplitudes triggered by each AP during the trains. The pronounced increase in EPSC amplitudes during the trains was parallel by a decrease in failure rates (Fig. $2 B)$. The mean increase in EPSC amplitude was $395 \pm 71 \%$ (mean \pm SEM; from $15.0 \pm 4.9$ to $53.4 \pm 8.5 \mathrm{pA} ; n=9$ ), whereas the mean $P_{\mathrm{f}}$ was reduced to $<22 \%$ of its initial value (from $0.67 \pm$ 0.07 to $0.15 \pm 0.04 ; n=9$ ) (Table 1 ) from the beginning to the end of the trains. Moreover, in all connections an increase in the potencies (from $42.0 \pm 9.7$ to $59.8 \pm 11.1 \mathrm{pA} ; n=9$ ) was also observed (Figs. $2 B, 4 B$, Table 1 ).

To determine quantal parameters $\left(N, q, P_{\mathrm{r}}\right)$ at these connections, we first used the simplest possible quantal model, the simple binomial model, and analyzed the data with a failure method. This model is based on the assumptions that all release sites are independent and $P_{\mathrm{r}}$ and $q$ are uniform across release sites. We also assumed no change in $q$ during the train of APs. $N_{\mathrm{F}(\mathrm{f})}$ was calculated from the measured potency amplitudes and failure rates $\left(P_{\mathrm{f}}\right)$ at the beginning and end of the stimulus trains. The $N_{\mathrm{F}(\mathrm{f})}$ is given by the smallest binomial $N$ at which the calculated potency was within $5 \%$ of the measured potency at the end of the train (see Materials and Methods). The $N_{\mathrm{F}(\mathrm{f})}$ was found to be a finite number in eight of nine pairs (Figs. $2 C, 3 B, 4 C$ ), ranging from 2 to $5(2.9 \pm 0.4 ; n=8)$ (Table 1$)$. There was only one exception in which the increase in potency during the train could not be explained solely by an increase in $P_{\mathrm{r}}$, indicating that some of our assumptions were violated. For the remaining eight pairs, $q$ and $P_{\mathrm{r}}$ were calculated at the beginning and end of the AP train. The initial $P_{\mathrm{r}}$ is remarkably low $(0.15 \pm 0.04 ; n=8$; ranging from 0.06 to 0.39 ), allowing a large enhancement during repetitive activation. By the end of the AP train, the mean $P_{\mathrm{r}}$ had increased by $383 \pm 84 \%$ (to $0.53 \pm 0.04 ; n=8$ ), which is almost identical to the mean increase in EPSC amplitudes (395 $\pm 71 \% ; n=9)$. The averaged $q$ was $39.7 \mathrm{pA}$, with a large variability among cells $(\mathrm{CV}=$ 0.71 ); individual values ranged from 13.9 to $99.2 \mathrm{pA}$ (Table 1 ).
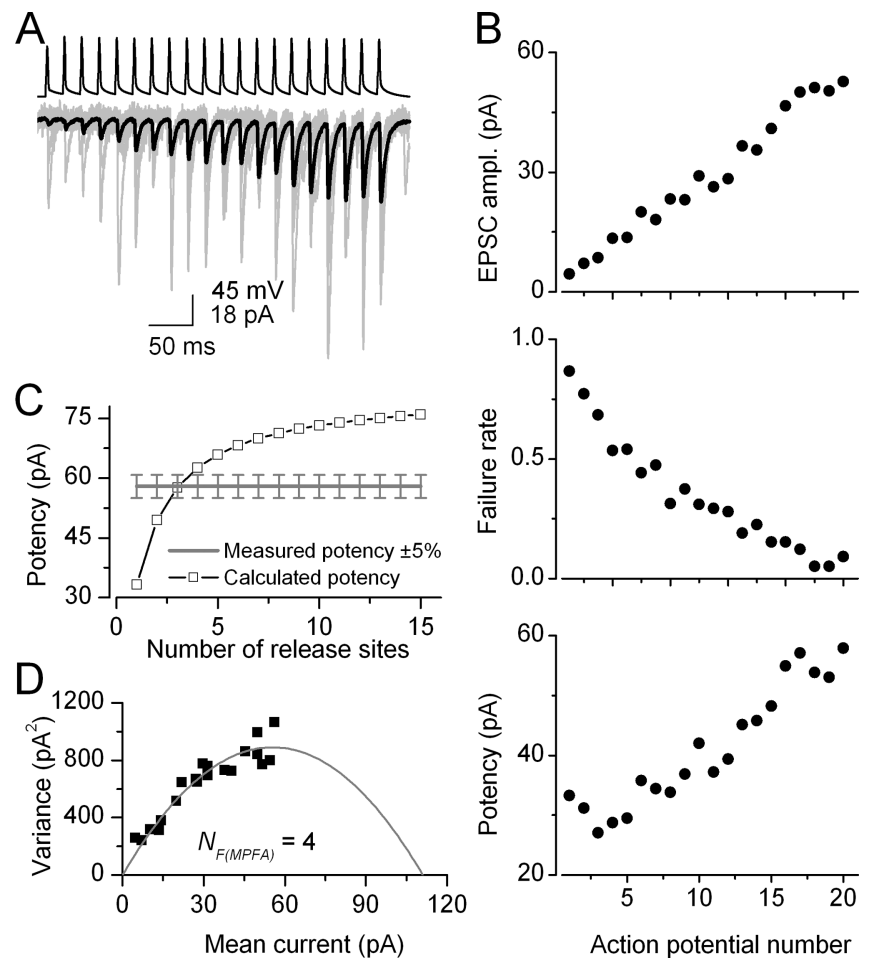

Figure 2. Short-term facilitation of unitary EPSCs evoked by a CA1 PC in an oriens-alveus IN (pair, AB383). A, Trains of action potentials (top) in the presynaptic PC evoke facilitating EPSCS in the IN (individual traces, light gray; averaged EPSC, black). B, Peak amplitudes of averaged EPSCs, failure rates, and potency amplitudes (averaged EPSCs excluding failures) are plotted as a function of action potential number. $C$, Using a simple binomial model with the failure method, we calculated the potency amplitudes at high $P_{r}$ conditions (open symbols) for integer numbers of $N$ ranging from 1 to 15 (for calculation see Materials and Methods). $N_{\mathrm{F}(f)}$ equals the smallest binomial $N$ (3) at which the calculated potency is within $5 \%$ of the measured potency at the end of the train. D, Mean current and the variance values of the postsynaptic responses were calculated at each AP of the train and a multinomial quantal model was fitted to the data, resulting in an $N_{\mathrm{F}(\mathrm{MPFA})}$ of 4 , a $q$ of 24.7 $\mathrm{pA}$, and $P_{\mathrm{r}}$ ranging from 0.05 to 0.49 (same pair as shown in $A-C$ ).

To verify the results obtained with the simple binomial model, we have used an independent method to determine the number of synaptic junctions between CA1 PCs and oriens-alveus INs. After paired recordings, the slices were fixed, intracellularly injected biocytin was visualized, and detailed LM and EM were performed (Figs. 3, 4) to establish the location and number of synaptic specializations between the PC axons and the IN dendrites. Twenty-eight of 53 synaptically connected pairs were processed for LM and EM analysis. In 8 of 28 pairs, full recovery of the recorded cells and the completeness of biocytin filling (with the exception of the IN axon; see Materials and Methods) were established. Of these eight pairs, six pairs were reconstructed at the LM level (Figs. 3D, $4 E$ ), and all places at which the presynaptic PC axon was within $1 \mu \mathrm{m}$ from the postsynaptic IN soma or dendrites were marked. All of these potential contact points were subsequently examined at the EM level after serial sectioning. If the presynaptic axon made a direct contact with the postsynaptic IN, the contact was considered a synaptic junction, only if the following criteria were fulfilled: (1) rigid apposition of presynaptic and postsynaptic membranes, (2) widening of the extracellular space in the synaptic cleft, (3) and clustering of small synaptic vesicles at the release site (Figs. 3F, 4G). The number of EMdetermined synaptic junctions in the examined connections $\left(N_{\mathrm{EM}}\right)$ ranged between one and six, with a mean of $2.8 \pm 0.8(n=$ 6) (Table 1). Our result is in agreement with several reports demonstrating that hippocampal and cortical PCs and dentate gran- 
Table 1. Quantal parameters of synaptic transmission between CA1 PCs and INs as determined with a failure method and a simple binomial model

\begin{tabular}{|c|c|c|c|c|c|c|c|c|c|c|c|c|c|c|}
\hline \multirow[b]{2}{*}{ Cells } & \multirow[b]{2}{*}{$\begin{array}{l}\text { Cell } \\
\text { type }\end{array}$} & \multicolumn{4}{|c|}{ Beginning of the train (low $P_{\mathrm{r}}$ condition) } & \multicolumn{4}{|c|}{ End of the train (High $P_{r}$ condition) } & \multirow[b]{2}{*}{$\begin{array}{l}\text { Calculated } \\
N_{\mathrm{F}(\mathrm{f})}\end{array}$} & \multirow[b]{2}{*}{$\begin{array}{l}\text { Measured } \\
N_{\mathrm{EM}} \\
\end{array}$} & \multirow[b]{2}{*}{$N_{\mathrm{EM}} / N_{\mathrm{F}(f)}$} & \multirow[b]{2}{*}{$P_{\text {r ratio }}$} & \multirow[b]{2}{*}{$\begin{array}{l}\text { EPSC } \\
\text { facilitation }\end{array}$} \\
\hline & & $\begin{array}{l}\text { Measured } \\
\text { failure rate }\end{array}$ & $\begin{array}{l}\text { Measured } \\
\text { potency }(\mathrm{pA})\end{array}$ & $\begin{array}{l}\text { Calculated } \\
P_{\mathrm{r}}\end{array}$ & $\begin{array}{l}\text { Calculated } \\
q(\mathrm{pA})\end{array}$ & $\begin{array}{l}\text { Measured } \\
\text { failure rate }\end{array}$ & $\begin{array}{l}\text { Measured } \\
\text { potency }(\mathrm{pA})\end{array}$ & $\begin{array}{l}\text { Calculated } \\
P_{\mathrm{r}}\end{array}$ & $\begin{array}{l}\text { Calculated } \\
q(\mathrm{pA})\end{array}$ & & & & & \\
\hline AB312 & $0-B i$ & 0.22 & 56.7 & 0.39 & 37.3 & 0.04 & 78.3 & 0.67 & 37.7 & 3 & 4 & 1.33 & 1.7 & 1.7 \\
\hline AB375 & ND & & & & & & & & & & 6 & & & \\
\hline AB376 & ND & 0.67 & 18.3 & & & 0.10 & 38.8 & & & $\infty$ & & & & 5.9 \\
\hline AB377 & $0-L M$ & 0.81 & 33.7 & 0.10 & 32.0 & 0.20 & 42.9 & 0.55 & 31.1 & 2 & 3 & 1.50 & 5.5 & 5.4 \\
\hline AB378 & ND & & & & & & & & & & 1 & & & \\
\hline AB383 & 0 -LM & 0.82 & 31.6 & 0.06 & 29.6 & 0.06 & 54.9 & 0.60 & 28.5 & 3 & & & 9.3 & 9.0 \\
\hline AB390 & ND & 0.83 & 30.6 & 0.09 & 29.2 & 0.29 & 39.2 & 0.46 & 30.2 & 2 & 1 & 0.50 & 5.1 & 5.2 \\
\hline AB534 & ND & 0.57 & 17.0 & 0.13 & 13.9 & 0.11 & 27.0 & 0.43 & 14.1 & 4 & & & 3.2 & 3.3 \\
\hline AB537 & $0-B i$ & 0.87 & 102.6 & 0.07 & 99.2 & 0.34 & 126.9 & 0.42 & 100.3 & 2 & & & 6.3 & 6.4 \\
\hline AB544 & 0 -LM & 0.61 & 17.8 & 0.09 & 14.7 & 0.05 & 35.6 & 0.45 & 15.1 & 5 & 2 & 0.40 & 4.7 & 4.9 \\
\hline AB545 & ND & 0.59 & 69.8 & 0.23 & 61.8 & 0.13 & 94.7 & 0.64 & 64.4 & 2 & & & 2.8 & 2.9 \\
\hline Mean & & 0.67 & 42.01 & 0.15 & 39.72 & 0.15 & 59.81 & 0.53 & 40.19 & 2.88 & 2.83 & 0.93 & 4.83 & 4.95 \\
\hline SEM & & 0.07 & 9.68 & 0.04 & 10.00 & 0.04 & 11.12 & 0.04 & 10.21 & 0.40 & 0.79 & 0.28 & 0.84 & 0.71 \\
\hline$n$ & & 9 & 9 & 8 & 8 & 9 & 9 & 8 & 8 & 8 & 6 & 4 & 8 & 9 \\
\hline
\end{tabular}

Potency, Mean postsynaptic response excluding failures; ND, not determined. Pairs for which only $N_{\mathrm{EM}}$ is shown (AB375 and AB378) were monosynaptically connected and exhibited short-term facilitation but failed to pass all of our criteria for detailed functional analysis. Some measured parameters for these pairs are as follows. For $\mathrm{AB} 375$, low $P_{\mathrm{r}} \cdot P_{\mathrm{f}}=0.61$, potency $=21.0 \mathrm{pA} ;$ high $P_{\mathrm{r}} \cdot P_{\mathrm{f}}=0.14$, potency $=36.4 \mathrm{pA} ; \mathrm{EPSC}$ facilitation $=3.9$. For $\mathrm{AB} 378$, low $P_{\mathrm{r}} \cdot P_{\mathrm{f}}=0.88$, potency $=21.3 \mathrm{pA}$; high $P_{\mathrm{r}} \cdot P_{\mathrm{f}}=0.60$, potency $=22.3 \mathrm{pA}$; EPSC facilitation $=3.4$.

ule cells excite their target INs through few release sites (ranging from 1 to 7) (Gulyas et al., 1993; Buhl et al., 1997; Geiger et al., 1997; Lawrence et al., 2004).

The number of functionally $\left(N_{\mathrm{F}(\mathrm{f})}=2.9\right.$; range, $\left.2-5\right)$ and structurally $\left(N_{\mathrm{EM}}=2.8\right.$; range, $\left.1-6\right)$ determined release sites had very similar means and ranges, indicating that a simple binominal model could adequately describe our experimental data.

A possible reason for the agreement between $N_{\mathrm{F}(\mathrm{f})}$ and $N_{\mathrm{EM}}$, however, may be that our methods are insensitive to changes in $q$. In other words, changes in $q$ during the AP trains may have a negligible effect on the estimated $N_{\mathrm{F}(\mathrm{f})}$, and therefore the $N_{\mathrm{EM}} /$ $N_{\mathrm{F}(\mathrm{f})}$ ratio would still remain close to unity. To test this possibility, we performed simulations in which we systematically increased the $q$ from the beginning to the end of the trains (from 10 to $100 \%$ increase in $q$ with $10 \%$ increments) and tested the effect of this increase on the calculated $N_{\mathrm{F}(\mathrm{f})}$. As little as a $10 \%$ change in $q$ resulted in the reduction of $N_{\mathrm{F}}$ from 2.9 to 2.4 . An $\sim 20 \%$ change in $q$ halved the estimated $N_{\mathrm{F}(\mathrm{f})}$, an effect that is well above the detectability of our EM method. Thus, our simulations demonstrate that as little as a $10-20 \%$ change in $q$ causes a robust reduction in the estimated $N_{\mathrm{F}(\mathrm{f})}$, and therefore the good agreement between $N_{\mathrm{EM}}$ and $N_{\mathrm{F}(\mathrm{f})}$ must be the reflection of unaltered $q$ during the AP trains.

There are two possible explanations of a constant $q$ during the AP train. Either the glutamate concentration waveform in the synaptic cleft after the arrival of an action potential remains similar during the train, or postsynaptic AMPA receptors are already saturated by the synaptically released transmitter at low $P_{\mathrm{r}}$ conditions. If postsynaptic AMPA receptors were already fully occupied at low $P_{\mathrm{r}}$ conditions, an increase in synaptic glutamate concentration caused by either multivesicular release or spillover would remain unnoticed; however, if the postsynaptic AMPA receptor occupancy was low, the postsynaptic current would faithfully (but not necessarily linearly) monitor alterations in the synaptic transmitter concentration waveform. To estimate the postsynaptic receptor occupancy at these synapses, we determined the upper limits of occupancy (Silver et al., 1996) at two single-site connections. Upper limits of peak open probability of 0.54 and 0.45 were calculated from the mean currents and the largest EPSCs in each single synapse pair (mean, 46.6 and $28.1 \mathrm{pA}$; maximum, 86 and $62 \mathrm{pA}$ ). Given a maximal open probability of
0.84 (Andrasfalvy and Magee, 2001), the upper limits of receptor occupancy of 0.64 and 0.53 were calculated. This result demonstrates that postsynaptic AMPA receptors are far from saturation at these synapses and that the unaltered $q$ under different $P_{\mathrm{r}}$ conditions is the consequence of unchanged glutamate concentration transients in the synaptic cleft.

Despite the good agreement between the mean of $N_{\mathrm{F}(\mathrm{f})}$ and $N_{\mathrm{EM}}$, when we compared these values in the four cell pairs in which both of them could be determined, $N_{\mathrm{F}(\mathrm{f})}$ never matched $N_{\mathrm{EM}}$ (Table 1). This discrepancy, together with the large variability in the estimated $q$ among cells, indicated that our simple binomial model with no variances in quantal parameters is likely to represent an oversimplification. Indeed, when we examined the variance in the peak of successful EPSC amplitudes of the two single-site connections, type I (intrasite) quantal CVs of 0.40 and 0.41 were found. We also measured the total variance in the peak of successful EPSCs in multisite connections under very low $P_{\mathrm{r}}$ conditions (see Materials and Methods). Assuming that each release site has the same intrasite variance $\left(C V_{\mathrm{I}}=0.4\right)$, a mean intersite $C V_{\text {II }}$ of $0.37 \pm 0.08(n=3)$ was calculated. Thus, our experimental data clearly demonstrated the presence of significant intrasite and intersite quantal variances. Interestingly, the intraconnection intersite CV (0.37) was lower than the interconnection variations among the $q(\mathrm{CV}=0.71)$.

To investigate whether incorporating type I and II quantal variances into our model (multinomial quantal model with uniform $P_{\mathrm{r}}$ ) results in a better agreement between functionally and structurally determined $N$, we used a recently developed analysis method called MPFA (Silver et al., 1998; Reid and Clements, 1999; Clements and Silver, 2000; Meyer et al., 2001; Silver, 2003). This method takes advantage of the known parabolic relationship between the means and variances of binomial distributions. Quantal parameters are extracted after fitting the mean versus variance plot with a parabola (Figs. $2 D, 3 C, 4 D$ ). The mean and variance values were calculated for EPSCs throughout the AP trains, reflecting different $P_{\mathrm{r}}$ conditions. In all nine pairs, the calculated $N_{\mathrm{F}(\mathrm{MPFA})}$ was a finite number ranging from 1.4 to 4.7 $(3.1 \pm 0.4 ; n=9)$. Because the number of release sites should be a positive integer, we rounded the $N_{\mathrm{F} \text { (MPFA) }}$ values (range, 1-5; mean $=3.1 \pm 0.4)$ and compared them with the values obtained with the failure method. The mean of $N_{\mathrm{F}(\mathrm{f})}$ was almost identical to 


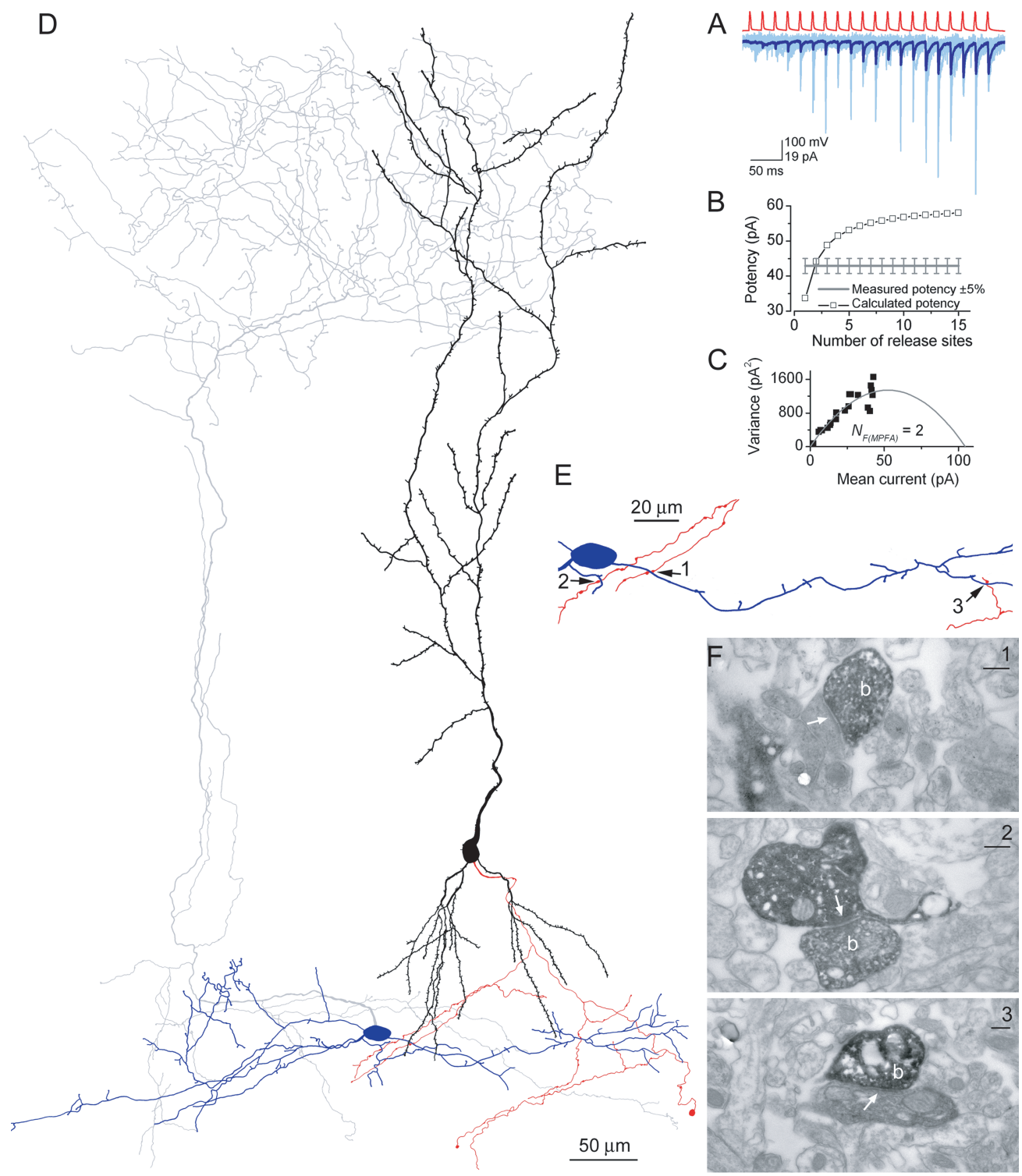

Figure 3. Functional and structural determination of the number of release sites for a PC-IN pair. $A$, Trains of presynaptic APs (red traces) evoked EPSCs in the postsynaptic IN (pair, AB377), which showed robust short-term facilitation (individual traces, light blue; averaged trace, dark blue). B, Potency amplitudes were calculated with a simple binomial model for integer Ns from 1 to 15 . The calculated potency at $N=2$ was almost identical to the measured potency at the end of the stimulus train, yielding $N_{\mathrm{F}(f)}$ of 2 . C, Multiple probability fluctuation analysis with a multinomial model also resulted in an $N_{\mathrm{F}(\mathrm{MPFA})}$ of 2. The quantal size is $39.6 \mathrm{pA}$, and the $P_{\mathrm{r}}$ ranges from 0.07 to 0.39 . D, LM reconstruction of the biocytin-labeled cells. The soma and dendrites of the presynaptic $\mathrm{PC}$ are shown in black; its axon arbor is red. The IN is classified as an 0 -LM cell based on the location of the soma and dendrites (blue) in the alveus and the extensive arborizations of its axon (gray) in the stratum lacunosum-moleculare. E, Locations of the three synaptic contacts (arrows) are shown at a higher magnification. Only parts of the IN and the PC are shown that establish the contacts. $F$, Electron microscopic images of the synaptic junctions (arrows) between three PC axon terminals (b) and the postsynaptic dendrites. Scale bars, $0.2 \mu \mathrm{m}$.

that of $N_{\mathrm{F}(\mathrm{MPFA})}$ (Tables 1,2), with the notable exception that in the pair in which $N_{\mathrm{F}(\mathrm{f})}$ was infinite, an $N_{\mathrm{F}(\mathrm{MPFA})}$ of 5 was obtained. The MPFA and the failure method also yielded very similar values of $P_{\mathrm{r}}$ (at the beginning, 0.13 and 0.15 ; at the end, 0.47 and 0.53 ) and $q$ ( 37.5 vs $39.7 \mathrm{pA}$ ). It is important to note that quantal parameters obtained with MPFA are prone to sampling errors if the $P_{\mathrm{r}}$ does not exceed 0.5 under the highest $P_{\mathrm{r}}$ condition (Silver, 2003). To estimate potential errors attributable to a limited number of traces obtained at low and high $P_{\mathrm{r}}$ conditions, we performed a series of Monte Carlo simulations (see Materials and Methods). Our simulations predicted that in half of the cases, MPFA correctly estimated the number of functional release sites for binomial Ns ranging from 1 to 5 , and in only $16 \%$ of the cases $N_{\mathrm{F}(\mathrm{MPFA})}$ differed from the binomial $N$ by $>1$.

Finally, when we compared $N_{\mathrm{F}(\mathrm{MPFA})}$ and $N_{\mathrm{EM}}$ in those pairs in which both were determined, we found that $N_{\mathrm{F}}$ was identical to $N_{\text {EM }}$ in two of four cases; in the remaining two pairs it overestimated and underestimated it by 1 (Table 2). This is remarkably similar to the prediction of our simulations, showing that MPFA correctly determines the $N$ in $\sim 50 \%$ of the cases and an error of 1 is obtained in the remaining cases. In pair $\mathrm{AB} 377, N_{\mathrm{F}(\mathrm{MPFA})}$ was 2 and $N_{\mathrm{EM}}$ was 3 (Fig. 3). To understand the possible reasons for this discrepancy, we performed detailed analysis of this connection. By examining the kinetics of unitary EPSCs, large heterogeneities were found in both the rise time (RT) and the decay time. The distribution of 10-90\% RT of successful events was skewed toward larger values (Fig. 5A). Most of the events had 10-90\% RT $<500 \mu \mathrm{sec}$, whereas a small population had $10-90 \%$ RTs between 0.7 and $5 \mathrm{msec}$. A possible explanation of these data is that some synapses produced EPSCs with a slow RT, whereas 


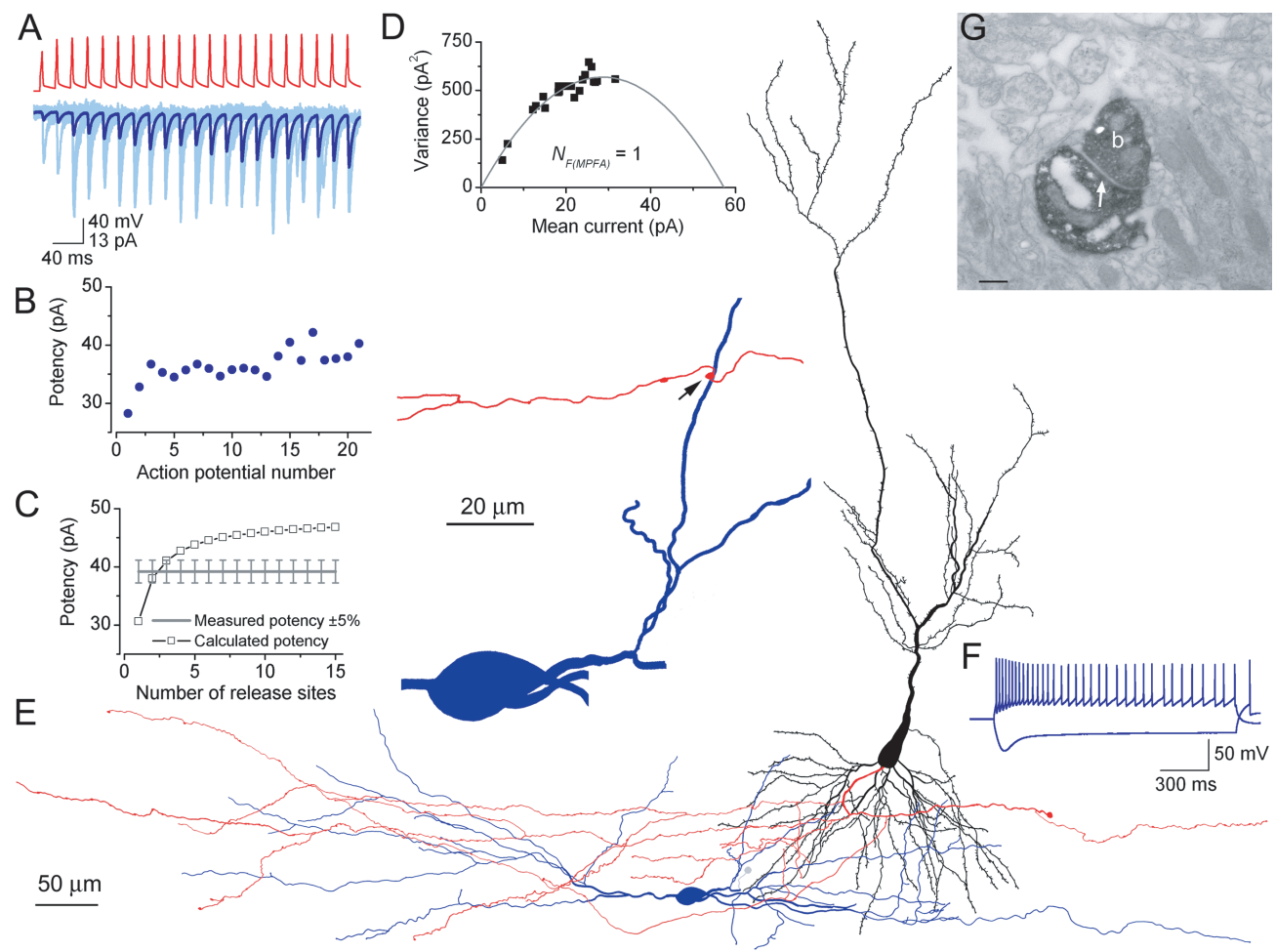

Figure 4. Determination of $N_{\mathrm{F}}$ and $N_{\mathrm{EM}}$ for a $\mathrm{PC}-\mathrm{IN}$ pair. A, Postsynaptic responses (individual traces, light blue; averaged trace, dark blue) evoked by a $\mathrm{PC}$ (action potentials in red) in an oriens-alveus IN (pair, AB390) show a pronounced short-term facilitation. B, Potency amplitudes are plotted against action potential numbers during trains of presynaptic APs at $50 \mathrm{~Hz}$. Only a slight increase in the potency was observed, although the $P_{f}$ is reduced from 0.83 to 0.29 from the beginning to the end of the train. $C$, From the measured $P_{f}$ and the potency amplitudes at the beginning and end of the train, $N_{\mathrm{F}(\mathrm{f})}$ of 2 was obtained by using the failure method with a simple binomial model. $D$, Parabolic fit to the mean versus variance plot resulted in an estimate of $N_{\mathrm{F}(\mathrm{MPFA})}$ of 1 , a $q$ of $30.6 \mathrm{pA}$, and $P_{r}$ ranging from 0.10 to 0.51 . E, Light microscopic reconstruction of the presynaptic $\mathrm{PC}$ (soma and dendrites are in black and axons are in red) and the soma and dendrites of the IN (blue). The main axon of the IN (gray) was truncated during slicing. Inset shows the location of the contact site at a higher magnification. $F$, Responses of the IN to a depolarizing and a hyperpolarizing current pulse ( $\pm 200 \mathrm{pA}$ ). G, An electron micrograph showing the synaptic junction (arrow) between the presynaptic bouton (b) and the postsynaptic dendrite. Scale bar, $0.2 \mu \mathrm{m}$.

others had a fast RT. Dendritic filtering of EPSCs originating at distal positions in theory could explain the differences in EPSC kinetics. In agreement with this possibility, two synaptic junctions were found at distances of $\sim 20 \mu \mathrm{m}$, and one was found at $\sim 160 \mu \mathrm{m}$ from the soma (Fig. $3 E$ ). If release is independent at each of these release sites, the fast rising events should include those that originate from only the proximal synapses (fast rising, fast decaying) and those that result from the co-release at the distal and either of the proximal sites (fast rising, slow decaying). We have subtracted the fast-rising, fast-decaying averaged EPSC from the fast-rising, slow-decaying one. The resulting subtracted trace had a waveform that was almost identical to the averaged slow-rising EPSCs (Fig. 5B-D), confirming our prediction. Together, the results of our kinetic and morphological analyses in-

Table 2. Quantal parameters of synaptic transmission between CA1 PCs and INs as determined with multiple probability fluctuation analysis and a multinomial quantal model

\begin{tabular}{|c|c|c|c|c|c|c|c|c|c|c|}
\hline \multirow[b]{2}{*}{ Cells } & \multicolumn{2}{|c|}{$\begin{array}{l}\text { Beginning of the train (low } P_{r} \\
\text { condition) }\end{array}$} & \multicolumn{2}{|c|}{$\begin{array}{l}\text { End of the train (high } P_{\mathrm{r}} \\
\text { condition) }\end{array}$} & \multirow[b]{2}{*}{$\begin{array}{l}\text { Calculated } \\
q(\mathrm{pA})\end{array}$} & \multirow[b]{2}{*}{$\begin{array}{l}\text { Calculated } \\
N_{\text {F(MPFA })} \\
\end{array}$} & \multirow[b]{2}{*}{$\begin{array}{l}\text { Rounded } \\
N_{\text {F(MPFA) }} \\
\end{array}$} & \multirow[b]{2}{*}{$\begin{array}{l}\text { Measured } \\
N_{\mathrm{EM}} \\
\end{array}$} & \multirow[b]{2}{*}{$N_{\mathrm{EM}} / N_{\text {F(MPFA) }}$} & \multirow[b]{2}{*}{$\begin{array}{l}\text { EPSC } \\
\text { facilitation }\end{array}$} \\
\hline & $\begin{array}{l}\text { Measured EPSC } \\
\text { ampl. (pA) }\end{array}$ & $\begin{array}{l}\text { Calculated } \\
P_{\mathrm{r}}\end{array}$ & $\begin{array}{l}\text { Measured EPSC } \\
\text { ampl. (pA) }\end{array}$ & $\begin{array}{l}\text { Calculated } \\
P_{\mathrm{r}}\end{array}$ & & & & & & \\
\hline $\begin{array}{l}A B 312 \\
A B 375\end{array}$ & 48.9 & 0.32 & 80.5 & 0.53 & 36.3 & 3.8 & 4 & $\begin{array}{l}4 \\
6\end{array}$ & 1 & 1.6 \\
\hline AB376 & 6.2 & 0.07 & 33.0 & 0.36 & 17.2 & 4.7 & 5 & & & 5.3 \\
\hline $\begin{array}{l}A B 377 \\
A B 378\end{array}$ & 6.9 & 0.07 & 41.3 & 0.39 & 39.6 & 2.3 & 2 & $\begin{array}{l}3 \\
1\end{array}$ & 1.5 & 6.0 \\
\hline AB383 & 5.9 & 0.05 & 54.2 & 0.49 & 24.7 & 4.1 & 4 & & & 9.3 \\
\hline AB390 & 5.6 & 0.10 & 29.3 & 0.51 & 30.6 & 1.4 & 1 & 1 & 1 & 5.2 \\
\hline AB534 & 10.3 & 0.15 & 30.0 & 0.43 & 17.7 & 3.6 & 4 & & & 2.9 \\
\hline AB537 & 13.4 & 0.04 & 89.3 & 0.30 & 87.4 & 3.1 & 3 & & & 6.6 \\
\hline AB544 & 8.7 & 0.16 & 35.2 & 0.64 & 16.4 & 3.0 & 3 & 2 & 0.67 & 4.1 \\
\hline AB545 & 29.0 & 0.20 & 87.4 & 0.59 & 67.2 & 1.9 & 2 & & & 3.0 \\
\hline Mean & 14.99 & 0.13 & 53.34 & 0.47 & 37.46 & 3.11 & 3.11 & 2.83 & 1.04 & 4.89 \\
\hline SEM & 4.89 & 0.03 & 8.50 & 0.04 & 8.20 & 0.36 & 0.42 & 0.79 & 0.17 & 0.77 \\
\hline$n$ & 9 & 9 & 9 & 9 & 9 & 9 & 9 & 6 & 4 & 9 \\
\hline
\end{tabular}

ampl., Amplitude. 
A

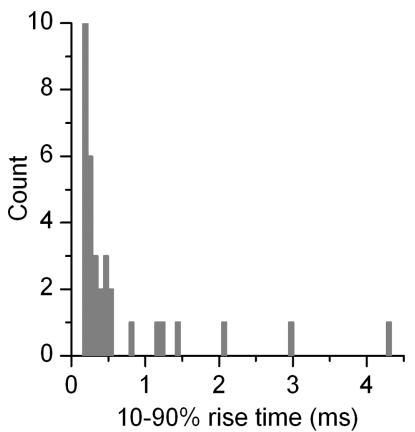

C

Fast rising EPSCs

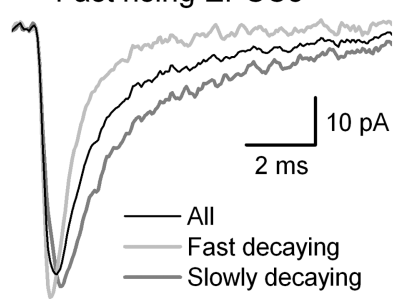

B

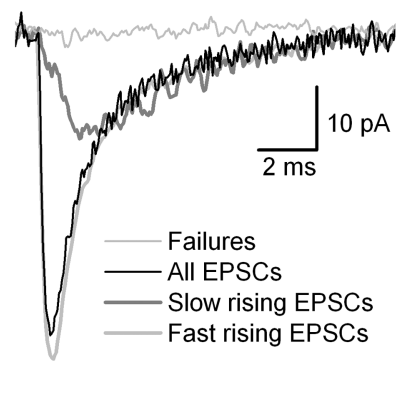

D

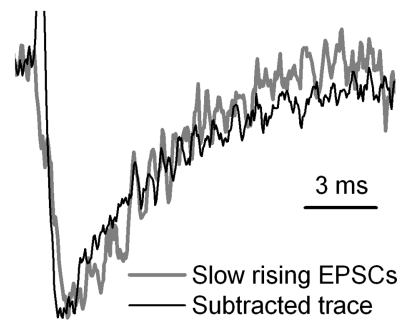

Figure 5. Kinetic properties of unitary EPSCs evoked by a PC on an IN. A, Distribution of $10-90 \%$ RTs of successful events evoked by the 16th AP of the presynaptic train (pair, AB377; same as shown in Fig. 3). The distribution is skewed toward larger values. Most of the EPSCs had a $10-90 \%$ RT $<500 \mu$ sec, but seven events showed an RT $>0.7 \mathrm{msec}$. The distribution suggests more than one population of events according to their rise times. $B$, Superimposed averaged traces with different kinetics. The average of failures is shown in gray and that of all EPSCS is black. Successful events were grouped according to their $10-90 \%$ RTs $(A)$, and the averaged traces are shown in gray and light gray thick traces. C, Fast-rising EPSC s were grouped according to their decay times to fast-and slow-decaying events. The $10-90 \%$ RTs of the two groups were slightly different (fast decaying, $0.18 \mathrm{msec}$; slow decaying, $0.37 \mathrm{msec}$ ) and their amplitudes were almost identical (fast decaying, $56.4 \mathrm{pA}$; slow decaying, $55.2 \mathrm{pA}$ ), but their weighted decay time constants differed markedly (fast decaying, $0.88 \mathrm{msec}$; slow decaying, $2.7 \mathrm{msec}$ ). $D$, The decay kinetics of the slow-rising EPSCs (gray trace) is compared with the arithmetic difference between the fast-rising, slow-decaying and fast-rising, fast-decaying EPSCs (black trace). The decay of the two traces overlaps well, indicating that the fast-rising, slow-decaying events are the superimposition of slow-rising and fast-rising fast-decaying EPSCs. The peak amplitudes of the traces were normalized.

dicate that slow-rising EPSCs are very likely caused by dendritic filtering of distally generated synaptic currents. The most important consequence of the widespread locations of synapses on the postsynaptic IN dendritic tree is that the distally generated EPSCs contribute negligibly $(<10 \%)$ to the peak of the averaged EPSC (reached within $400 \mu \mathrm{sec}$ ) as recorded somatically under voltage clamp. Thus, our estimate of $N_{\mathrm{F}}(2)$ is in good agreement with the presence of two proximal synaptic junctions. Thus, in this connection, the incorporated $37 \% C V_{\text {II }}$ was probably less than the real CV between the release sites, very likely because of the extremely large difference in the distance of one of the synapses from the soma.

\section{Discussion}

In the present study we have combined physiological, modeling, and anatomical approaches to determine the quantal parameters and identify the origin of alterations of EPSCs during short-term facilitation at hippocampal glutamatergic synapses. We found a good agreement between the mean number of release sites as determined with a simple binomial quantal model and the mean of $N_{\mathrm{EM}}$; however, $N_{\mathrm{F}(\mathrm{f})}$ never matched $N_{\mathrm{EM}}$ when they were compared in those individual pairs in which both could be deter-

mined. Our data demonstrate a sizable type I (0.40) and II (0.37) quantal CV at these glutamatergic synaptic connections. Indeed, when quantal variances were included in our model (multinomial quantal model), the functional prediction of the number of release sites ( $N_{\mathrm{F} \text { (MPFA) }}$ ) matched the $N_{\mathrm{EM}}$ in two of four cases; in the remaining two pairs, it resulted in an error of 1 . Our results also revealed that the interconnection intersite variation in the quantal size $(\mathrm{CV}=0.7)$ is larger than that found among synapses made by a single presynaptic cell onto one of its target cells (intraconnection intersite variability; $\mathrm{CV}=0.37$ ). We also show that the robust short-term facilitation of postsynaptic responses is the sole consequence of an increase in $P_{\mathrm{r}}$, whereas an up to 10-fold change in $P_{\mathrm{r}}$ does not cause any alteration in $q$. Our results demonstrate that a single EM-identified synaptic specialization corresponds to a single functional release site at cortical glutamatergic synapses. Furthermore, the same number of vesicles (probably one) is liberated on the arrival of an AP at a single release site even if the $P_{\mathrm{r}}$ is changed dramatically, within functionally relevant ranges.

\section{An increase in $P_{\mathrm{r}}$ is solely responsible for short-term facilitation}

Plastic changes at time scales from tens of milliseconds to a few seconds have been shown to dramatically affect the reliability of synapses and the way in which information is processed in cortical networks. Mechanisms underlying short-term facilitation of neocortical and hippocampal glutamatergic synapses have been investigated extensively (for review, see Thomson, 2000; Zucker and Regehr, 2002). It is generally agreed that an increase in the $P_{\mathrm{r}}$ occurs during facilitation; however, it is still debated whether the increase in $P_{\mathrm{r}}$ is solely responsible for the facilitation or whether postsynaptic modifications also take place. Several studies reported an exclusive presynaptic alteration (Gulyas et al., 1993; Stevens and Wang, 1995; Dobrunz and Stevens, 1997; Hanse and Gustafsson, 2001; Silver et al., 2003; Chen et al., 2004; Lawrence et al., 2004), but evidence has also been published supporting significant postsynaptic modifications, including an increased quantal size after multivesicular release (Oertner et al., 2002; Conti and Lisman, 2003) or removing the polyamine block from certain postsynaptic glutamate receptors (Rozov and Burnashev, 1999). To some extent, the reason for the discrepancy is likely attributable to differences in experimental approaches, such as the preparations, the age of the animals, and the identity of the synapses examined. Another important variable between these studies is the way the presynaptic fibers were stimulated. Some investigators used extracellular stimulations and others used paired recordings to activate presynaptic fibers. A major difference between these approaches is that although only a single axon is stimulated in paired recordings, an unknown number of fibers is activated with extracellular stimulations. By stimulating a large number of fibers, transmitter "cross talk" or "pooling" may occur among the large number of activated boutons, changing the synaptic glutamate concentration waveform and resulting in a significant alteration in $q$ when $P_{\mathrm{r}}$ is increased (Barbour and Hausser, 1997; Kullmann and Asztely, 1998). Such a change in the transmitter concentration waveform may be interpreted as the consequence of multivesicular release. On the other hand, several studies applied minimal extracellular stimulations to identify single release sites and reached the conclusion that $q$ is independent of $P_{\mathrm{r}}$ (Stevens and Wang, 1995; Dobrunz and Stevens, 1997; Hanse and Gustafsson, 2001). A potential drawback of these experiments is the subselection of certain fibers, and therefore the conclusions may hold true only for a minor sub- 
population of synapses (Stevens, 2003). In the present study, we have used paired recordings to avoid the above-mentioned uncertainties of extracellular stimulations, and our criteria for accepting a pair into the study did not include the constancy of potency under different $P_{\mathrm{r}}$ conditions. Our data are consistent with a model in which $q$ is independent of $P_{\mathrm{r}}$, and because postsynaptic receptor occupancy is low at the examined synapses, it is likely that multivesicular release and/or transmitter spillover does not occur.

\section{One-release site, one-vesicle hypothesis}

By examining inhibitory inputs of goldfish Mauthner cells, Korn et al. $(1981,1982)$ found a remarkable agreement between the functionally determined number of release sites using a binomial quantal model and the number of morphologically identified presynaptic axon terminals. This led to the formulation of the one-vesicle hypothesis (Korn et al., 1994): either no vesicle or only one vesicle is released at one release site after the arrival of a presynaptic action potential. Several recent studies tested the one-release site, one-vesicle hypothesis at mammalian central synapses and came to various conclusions (Auger et al., 1998; Wadiche and Jahr, 2001; Oertner et al., 2002; Schneggenburger et al., 2002; Conti and Lisman, 2003) (but see Gulyas et al., 1993; Stevens and Wang, 1995; Dobrunz and Stevens, 1997; Hanse and Gustafsson, 2001; Silver et al., 2003; Lawrence et al., 2004). As mentioned above, the discrepancy may be the consequence of technical differences, most notably distinctions in the way presynaptic axons were stimulated. The results of every study that used a combined physiological, modeling, and anatomical approach (Gulyas et al., 1993; Silver et al., 2003; our present work) are consistent with the one-release site, one-vesicle hypothesis.

We emphasize that clear distinctions have to be made between the following two possibilities: (1) multivesicular release does occur during transmission under physiological conditions, or (2) more than one vesicle can be released from single release sites within a short period of time. Our results cannot exclude the second possibility. Namely, if the $P_{\mathrm{r}}$ is drastically increased, for example, by changing the extracellular concentration of $\mathrm{Ca}^{2+}$ to $10 \mathrm{~mm}$ or by applying high osmolarity solutions (methods widely used to examine synaptic transmission), the release of more than one vesicle within a few milliseconds may be observed from a single release site of the axon terminals examined. Although we consider the conditions used in the present study to change $P_{\mathrm{r}}$ to be physiologically relevant, they are probably more pronounced than one would expect to take place in vivo, because hippocampal CA1 pyramidal cells fire only a few APs at high frequencies when the animal moves through the place field of the cell (Buzsaki, 2002). Thus, the dynamic range of these synapses is likely to be exploited to a lesser extent in vivo than in our study, making multivesicular release less probable than under our experimental conditions, during which signs of multivesicular release were not observed.

Our results also demonstrate that a single EM-identified synaptic specialization corresponds to a single functional release site at cortical glutamatergic connections. It has been shown that most hippocampal glutamatergic axon terminals have only one synaptic specialization and that a single specialization contains a large number of docked vesicles (Sorra and Harris, 1993; Schikorski and Stevens, 1997). Indeed, we also found only one presynaptic specialization at each axon terminal and a large number of small synaptic vesicles attached to the presynaptic specialization at identified synaptic contacts. If each docked vesicle represented a release site, the number of functional release sites would be several dozens in each of our connections. This is clearly different from our estimates obtained either with the failure method or with MPFA. Given an initial transmitter release probability of 0.15 and the number of vesicles of a few dozen, a very low vesicle release probability $(<0.005)$ can be calculated for a single AP at these synapses. The determination that an EMidentified synaptic junction, instead of an individual docked vesicle, corresponds to a functional release site makes a fundamental contribution to our understanding of how to formulate functionally testable predictions from ultrastructural data.

\section{References}

Abbott LF, Varela JA, Sen K, Nelson SB (1997) Synaptic depression and cortical gain control. Science 275:220-224.

Ali AB, Thomson AM (1998) Facilitating pyramid to horizontal oriensalveus interneurone inputs: dual intracellular recordings in slices of rat hippocampus. J Physiol (Lond) 507:185-199.

Andrasfalvy BK, Magee JC (2001) Distance-dependent increase in AMPA receptor number in the dendrites of adult hippocampal CA1 pyramidal neurons. J Neurosci 21:9151-9159.

Auger C, Kondo S, Marty A (1998) Multivesicular release at single functional synaptic sites in cerebellar stellate and basket cells. J Neurosci 18:4532-4547.

Barbour B, Hausser M (1997) Intersynaptic diffusion of neurotransmitter. Trends Neurosci 20:377-384.

Buhl EH, Tamas G, Szilagyi T, Stricker C, Paulsen O, Somogyi P (1997) Effect, number and location of synapses made by single pyramidal cells onto aspiny interneurones of cat visual cortex. J Physiol (Lond) 500:689-713.

Buzsaki G (2002) Theta oscillations in the hippocampus. Neuron 33:325-340.

Chen G, Harata NC, Tsien RW (2004) Paired-pulse depression of unitary quantal amplitude at single hippocampal synapses. Proc Natl Acad Sci USA 101:1063-1068.

Clements JD, Silver RA (2000) Unveiling synaptic plasticity: a new graphical and analytical approach. Trends Neurosci 23:105-113.

Conti R, Lisman J (2003) The high variance of AMPA receptor- and NMDA receptor-mediated responses at single hippocampal synapses: evidence for multiquantal release. Proc Natl Acad Sci USA 100:4885-4890.

del Castillo J, Katz B (1954a) Quantal components of the end-plate potential. J Physiol (Lond) 124:560-573.

del Castillo J, Katz B (1954b) Statistical factors involved in neuromuscular facilitation and depression. J Physiol (Lond) 124:574-585.

Dittman JS, Kreitzer AC, Regehr WG (2000) Interplay between facilitation, depression, and residual calcium at three presynaptic terminals. J Neurosci 20:1374-1385.

Dobrunz LE, Stevens CF (1997) Heterogeneity of release probability, facilitation, and depletion at central synapses. Neuron 18:995-1008.

Geiger JRP, Lubke J, Roth A, Frotscher M, Jonas P (1997) Submillisecond AMPA receptor-mediated signaling at a principal neuron-interneuron synapse. Neuron 18:1009-1023.

Gulyas AI, Miles R, Sik A, Toth K, Tamamaki N, Freund TF (1993) Hippocampal pyramidal cells excite inhibitory neurons through a single release site. Nature 366:683-687.

Hanse E, Gustafsson B (2001) Factors explaining heterogeneity in shortterm synaptic dynamics of hippocampal glutamatergic synapses in the neonatal rat. J Physiol (Lond) 537:141-149.

Harrison J, Jahr CE (2003) Receptor occupancy limits synaptic depression at climbing fiber synapses. J Neurosci 23:377-383.

Ishikawa T, Sahara Y, Takahashi T (2002) A single packet of transmitter does not saturate postsynaptic glutamate receptors. Neuron 34:613-621.

Jack JJB, Larkman AU, Major G, Stratford KJ (1994) Quantal analysis of the synaptic excitation of CA1 hippocampal pyramidal cells. New York: Raven.

Kondo S, Marty A (1998) Synaptic currents at individual connections among stellate cells in rat cerebellar slices. J Physiol (Lond) 509:221-232.

Korn H, Triller A, Mallet A, Faber DS (1981) Fluctuating responses at a central synapse: $n$ of binomial fit predicts number of stained presynaptic boutons. Science 213:898-901.

Korn H, Mallet A, Triller A, Faber DS (1982) Transmission at a central 
inhibitory synapse. II. Quantal description of release, with a physical correlate for binomial $n$. J Neurophysiol 48:679-707.

Korn H, Sur C, Charpier S, Legendre P, Faber DS (1994) The one-vesicle hypothesis and multivesicular release. New York: Raven.

Kullmann DM, Asztely F (1998) Extrasynaptic glutamate spillover in the hippocampus: evidence and implications. Trends Neurosci 21:8-14.

Lawrence JJ, Grinspan ZM, McBain CJ (2004) Quantal transmission at mossy fibre targets in the CA3 region of the rat hippocampus. J Physiol (Lond) 554:175-193.

Losonczy A, Zhang L, Shigemoto R, Somogyi P, Nusser Z (2002) Cell type dependence and variability in the short-term plasticity of EPSCs in identified mouse hippocampal interneurones. J Physiol (Lond) 542:193-210.

Meyer AC, Neher E, Schneggenburger R (2001) Estimation of quantal size and number of functional active zones at the calyx of Held synapse by nonstationary EPSC variance analysis. J Neurosci 21:7889-7900.

Murthy VN, Sejnowski TJ, Stevens CF (1997) Heterogeneous release properties of visualized individual hippocampal synapses. Neuron 18:599-612.

Nimchinsky EA, Yasuda R, Oertner TG, Svoboda K (2004) The number of glutamate receptors opened by synaptic stimulation in single hippocampal spines. J Neurosci 24:2054-2064.

Nusser Z, Naylor D, Mody I (2001) Synapse-specific contribution of the variation of transmitter concentration to the decay of inhibitory postsynaptic currents. Biophys J 80:1251-1261.

Oertner TG, Sabatini BL, Nimchinsky EA, Svoboda K (2002) Facilitation at single synapses probed with optical quantal analysis. Nat Neurosci 5:657-964.

Oleskevich S, Clements J, Walmsley B (2000) Release probability modulates short-term plasticity at a rat giant terminal. J Physiol (Lond) 524:513-523.

Otis T, Zhang S, Trussell LO (1996) Direct measurement of AMPA receptor desensitization induced by glutamatergic synaptic transmission. J Neurosci 16:7496-7504.

Paulsen O, Heggelund P (1994) The quantal size at retinogeniculate synapses determined from spontaneous and evoked EPSCs in guinea-pig thalamic slices. J Physiol (Lond) 480:505-511.

Pouille F, Scanziani M (2004) Routing of spike series by dynamic circuits in the hippocampus. Nature 429:717-723.

Redman S (1990) Quantal analysis of synaptic potentials in neurons of the central nervous system. Physiol Rev 70:165-198.

Reid CA, Clements JD (1999) Postsynaptic expression of long-term potentiation in the rat dentate gyrus demonstrated by variance-mean analysis. J Physiol (Lond) 518:121-130.

Rozov A, Burnashev N (1999) Polyamine-dependent facilitation of postsynaptic AMPA receptors counteracts paired-pulse depression. Nature 401:594-598.

Scanziani M, Gahwiler BH, Charpak S (1998) Target cell-specific modulation of transmitter release at terminals from a single axon. Proc Natl Acad Sci USA 95:12004-12009.

Schikorski T, Stevens CF (1997) Quantitative ultrastructural analysis of hippocampal excitatory synapses. J Neurosci 17:5858-5867.

Schneggenburger R, Sakaba T, Neher E (2002) Vesicle pools and short-term synaptic depression: lessons from a large synapse. Trends Neurosci 25:206-212.

Silver RA (2003) Estimation of nonuniform quantal parameters with multiple-probability fluctuation analysis: theory, application and limitations. J Neurosci Methods 130:127-141.

Silver RA, Cull-Candy SG, Takahashi T (1996) Non-NMDA glutamate receptor occupancy and open probability at a rat cerebellar synapse with single and multiple release sites. J Physiol (Lond) 494:231-250.

Silver RA, Momiyama A, Cull-Candy SG (1998) Locus of frequencydependent depression identified with multiple-probability fluctuation analysis at rat climbing fibre-Purkinje cell synapses. J Physiol (Lond) 510:881-902.

Silver RA, Lubke J, Sakmann B, Feldmeyer D (2003) High-probability uniquantal transmission at excitatory synapses in barrel cortex. Science 302:1981-1984.

Sorra KE, Harris KM (1993) Occurrence and three-dimensional structure of synapses between individual radiatum axons and their target pyramidal cells in hippocampal area CA1. J Neurosci 13:3736-3748.

Stevens CF (2003) Neurotransmitter release at central synapses. Neuron 40:381-388.

Stevens CF, Wang Y (1995) Facilitation and depression at single central synapses. Neuron 14:795-802.

Thomson AM (2000) Facilitation, augmentation and potentiation at central synapses. Trends Neurosci 23:305-312.

Tsodyks MV, Markram H (1997) The neural code between neocortical pyramidal neurons depends on neurotransmitter release probability. Proc Natl Acad Sci USA 94:719-723.

Varela JA, Sen K, Gibson J, Fost J, Abbott LF, Nelson SB (1997) A quantitative description of short-term plasticity at excitatory synapses in layer $2 / 3$ of rat primary visual cortex. J Neurosci 17:7926-7940.

Wadiche JI, Jahr CE (2001) Multivesicular release at climbing fiberPurkinje cell synapses. Neuron 32:301-313.

Zador A (1998) Impact of synaptic unreliability on the information transmitted by spiking neurons. J Neurophysiol 79:1219-1229.

Zucker RS, Regehr WG (2002) Short-term synaptic plasticity. Annu Rev Physiol 64:355-405. 